\title{
Treatment of exacerbations as a predictor of subsequent outcomes in patients with COPD
}

This article was published in the following Dove Press journal:

International Journal of COPD

Peter MA Calverley,' Antonio R Anzueto, ${ }^{2}$ Daniel Dusser, ${ }^{3}$ Achim Mueller, ${ }^{4}$ Norbert Metzdorf, ${ }^{5}$ Robert A Wise ${ }^{6}$

'Clinical Science Centre, Institute of Ageing and Chronic Disease, University of Liverpool, Liverpool, UK; ${ }^{2}$ Pulmonary/ Critical Care, University of Texas and South Texas Veterans Health Care System, San Antonio, TX, USA; ${ }^{3}$ Department of Pneumology, Hôpital Cochin, AP-HP, Université Paris Descartes, Sorbonne Paris Cité, Paris, France; ${ }^{4}$ Biostatistics and Data Sciences Europe, Boehringer Ingelheim Pharma GmbH \& Co. KG, Biberach an der Riss, Germany; ${ }^{5}$ Respiratory Medicine, Boehringer Ingelheim Pharma $\mathrm{GmbH}$ \& $\mathrm{Co}$. KG, Ingelheim am Rhein, Germany; ${ }^{6}$ Division of Pulmonary and Critical Care Medicine, Department of Medicine, Johns Hopkins University School of Medicine, Baltimore, MD, USA

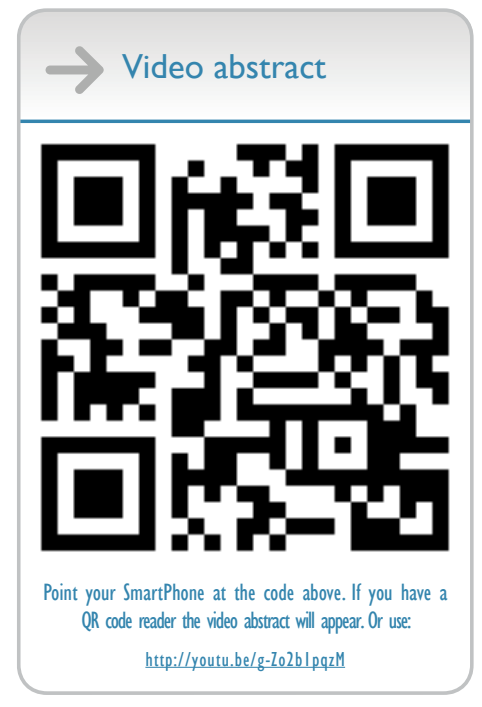

Correspondence: Peter MA Calverley Clinical Science Centre, Institute of Ageing and Chronic Disease, University of Liverpool, Longmoor Lane, Liverpool L9 7AL, UK Tel +44 I5I 5295886

Fax +44 I5I 5295888 Email pmacal@liverpool.ac.uk
Rationale: Exacerbations of COPD are managed differently, but whether treatment of one exacerbation predicts the likelihood of subsequent events is unknown.

Objective: We examined whether the treatment given for exacerbations predicted subsequent outcomes.

Methods: This was a post-hoc analysis of 17,135 patients with COPD from TIOtropium Safety and Performance In Respimat ${ }^{\circledR}$ (TIOSPIR ${ }^{\circledR}$ ). Patients treated with tiotropium with one or more moderate to severe exacerbations on study were analyzed using descriptive statistics, logistic and Cox regression analysis, and Kaplan-Meier plots.

Results: Of 8,061 patients with moderate to severe exacerbation(s), demographics were similar across patients with exacerbations treated with antibiotics and/or steroids or hospitalization. Exacerbations treated with systemic corticosteroids alone or in combination with antibiotics had the highest risk of subsequent exacerbation (HR: 1.21, $P=0.0004$ and HR: $1.33, P<0.0001$, respectively), and a greater risk of having a hospitalized (severe) exacerbation (HR: 1.59 and 1.63, $P<0.0001$, respectively) or death (HR: $1.50, P=0.0059$ and HR: $1.47, P=0.0002$, respectively) compared with exacerbations treated with antibiotics alone. Initial hospitalization led to the highest risk of subsequent hospitalization (all-cause or COPD related [severe exacerbation], HR: 3.35 and 4.31, $P<0.0001$, respectively) or death (all-cause or COPD related, HR: 3.53 and $5.54, P<0.0001$, respectively) versus antibiotics alone.

Conclusion: These data indicate that the way exacerbations are treated initially is a useful guide to the patient's subsequent clinical course. Factors that clinicians consider when making treatment choices require further clarification.

Keywords: tiotropium, TIOSPIR ${ }^{\circledR}$, severity, exacerbations of COPD, hospitalization

\section{Introduction}

The pharmacological treatment of acute exacerbations of COPD has changed relatively little over the last two decades. Oral corticosteroids are used to shorten the length of the exacerbation, ${ }^{1,2}$ reduce the risk of subsequent relapse, ${ }^{3}$ and are as effective when given for 5 as for 14 days. ${ }^{4}$ Antibiotics, which are given when patients meet the Anthonisen criteria for infected sputum, ${ }^{5}$ promote microbiological cure ${ }^{6}$ and possibly reduce the risk of relapse, ${ }^{7}$ both of which are important considerations for hospitalized patients. ${ }^{8}$ The prognosis is worse when hospitalization is needed than when patients can be cared for at home. ${ }^{9}$ These operational definitions of exacerbation have been widely adopted in clinical trials and by regulators.

While the treatment provided is likely to reflect physicians' best efforts at phenotyping the exacerbation based on the information available to them, more information is needed about what influences clinicians' or patients' treatment choices for the management of an exacerbation. The results of randomized, controlled trials show that 
the main effect of including an anti-inflammatory agent like an inhaled corticosteroid (ICS) in the maintenance treatment regimen is a reduction in the number of exacerbations treated with oral corticosteroids, ${ }^{10,11}$ even when the physician has been blinded to the preventive therapy being taken. Whether the chosen treatment regimen identifies patients at risk of subsequent relapse, and/or the occurrence of more serious events, remains unclear.

We have investigated the relationship between the treatment of exacerbations and subsequent patient outcomes using data collected as part of the TIOtropium Safety and Performance In Respimat ${ }^{\circledR}$ (TIOSPIR ${ }^{\circledR}$ ) trial, ${ }^{12,13}$ with the largest number of randomized patients with COPD followed in a long-term randomized trial to date. TIOSPIR data are helpful as all participants received the long-acting muscarinic antagonist (LAMA) tiotropium, a therapy recommended for maintenance treatment in all Global Initiative for Chronic Obstructive Lung Disease (GOLD) stages of COPD. ${ }^{14}$ As there were no differences in outcomes between the treatment arms, we have pooled the data and examined whether there were differences in the clinical characteristics of patients according to the treatment received for their first (index) acute on-treatment exacerbation, and whether the subsequent clinical course differed according to the treatment choices made during the management of this initial event.

\section{Methods}

\section{Study design}

TIOSPIR was a large $(\mathrm{N}=17,135)$, long-term $(2-3$ years follow-up), randomized, double-blind, double-dummy, parallelgroup, event-driven trial in patients with COPD. The trial design and methodology have been published previously. ${ }^{12,13}$ The trial was performed in accordance with the provisions of the Declaration of Helsinki, and the study protocol and procedures were approved by relevant institutional review boards and ethics committees (independent ethics committee Johns Hopkins Medicine Institutional Review Board, Baltimore, MD, USA). All the patients provided written informed consent.

\section{Study population}

Participants in TIOSPIR had a diagnosis of COPD with a post-bronchodilator $\mathrm{FEV}_{1} \leq 70 \%$ predicted and an $\mathrm{FEV}_{1} / \mathrm{FVC}$ ratio $\leq 0.70$ were aged $\geq 40$ years, with a smoking history of $\geq 10$ pack-years. All COPD medications were allowed except other inhaled anticholinergic agents and systemic corticosteroid medication at unstable ( $<6$ weeks) or high (chronic; equivalent of $10 \mathrm{mg}$ /day prednisolone) doses.
Patients whose first on-treatment exacerbation was moderate or severe were included in the analysis. Patients without exacerbations, or whose first exacerbation was mild, were excluded.

\section{Assessments}

At randomization, patients received once-daily tiotropium (Spiriva ${ }^{\circledR}$ [Boehringer Ingelheim, Ingelheim am Rhein, Germany]) via Respimat $5 \mu \mathrm{g}$ (two inhalations of $2.5 \mu \mathrm{g}$ ), Respimat $2.5 \mu \mathrm{g}$ (two inhalations of $1.25 \mu \mathrm{g}$ ), or HandiHaler ${ }^{\circledR}$ $18 \mu \mathrm{g}$, and the parallel HandiHaler or Respimat placebo. They were reviewed at Weeks 0,6 , and 12, and then every 12 weeks. At each visit, data about symptomatic exacerbations, and how these were treated, were collected. An independent mortality adjudication committee attributed the cause of each death.

Exacerbations were defined as the worsening of two or more major respiratory symptoms (dyspnea, cough, sputum, chest tightness, or wheezing) for $\geq 3$ days and requiring specified treatment changes. Following current practice, the severity of exacerbations was defined by the type of treatment received: moderate exacerbations required a prescription for antibiotics, systemic corticosteroids, or both (with no hospitalization) and severe exacerbations required hospitalization (due to COPD). While hospitalized patients commonly received antibiotics and/or corticosteroids, no therapy details were available; these events were analyzed separately (all groups are mutually exclusive).

The onset of exacerbation was defined as the onset of the first reported symptom; the end of exacerbation was decided by the investigator, based on clinical judgment. A period of at least 7 days between exacerbations was required to consider them as two separate exacerbations.

\section{Statistical analysis}

Post-hoc exploratory analyses on pooled treatment arms were performed to examine the relationship between the treatment choice for the index exacerbation and subsequent outcomes (exacerbation, hospitalization, death, or discontinuation including death).

HRs and 95\% CIs were calculated using a Cox proportional hazard regression model, with factors for treatment received for index exacerbation, ICS use at baseline, and exacerbation history. Negative binomial regression models with the same factors were used to estimate the annual rates and rate ratios.

To examine the immediate effect of the index exacerbation, we calculated the odds ratios for events within the first 60 days 
at risk following the index exacerbation, based on logistic regression, with factors for treatment received for index exacerbation, ICS use at baseline, and exacerbation history.

The day after the start of their index exacerbation, patients were considered to be at risk of adverse events requiring or prolonging hospitalization (subsequent hospitalization), or leading to death (including death due to COPD), or discontinuation. Time at risk of subsequent exacerbation started after the end of the index exacerbation.

\section{Results Study population}

On-treatment exacerbations were reported in 8,342 patients. Of these, 8,061 (96.6\%) patients who received antibiotics and/or systemic corticosteroids (moderate exacerbation), or who were hospitalized (severe exacerbation) for their index exacerbation, were included in the analysis. There were no differences in treatment received for the first ontreatment exacerbation between different regions of the world, except for slightly more patients from Asia being initially hospitalized.

Baseline characteristics by treatment for the first moderate or severe exacerbation are shown in Table 1. Most patients were male (67.8\%), mean age was 65 years, mean body mass index (BMI) was $26.1 \mathrm{~kg} / \mathrm{m}^{2}$, and mean smoking history was 45 pack-years. There were a higher proportion of patients who were underweight in the group that was hospitalized for their index exacerbation than in the groups that received antibiotics or steroids. Patients who were hospitalized for their index exacerbation had worse post-bronchodilator $\mathrm{FEV}_{1}$ percent predicted at baseline than those who received antibiotics only $(41.7 \%$ and $48.9 \%$, respectively). Therefore, patients whose index exacerbation was treated with antibiotics only were more likely to be in GOLD Stage I/II $(50.1 \%)$, while patients receiving systemic corticosteroids alone or in combination with antibiotics, or who were hospitalized for their index exacerbation, were predominantly in GOLD Stage III (43.7\%, 45.0\%, and 47.9\%, respectively). The mean duration of index exacerbations ranged from 15.6 to 21.1 days (Table 2).

The use of concomitant cardiovascular medication was similar between groups ( $52.2 \%$ overall); however, the presence of a history of cardiac disorders at baseline varied by treatment received for the index exacerbation, ranging from $22.4 \%$ of patients treated with systemic corticosteroids only to $32.6 \%$ of patients who required hospitalization. Patients with a history of heart failure appeared to be more likely to be hospitalized for an exacerbation than to receive antibiotic/corticosteroid treatment. Overall, $94.5 \%$ of patients were taking respiratory medication at study entry, $36.3 \%$ of whom received triple therapy (ICS/LAMA/long-acting $\beta_{2}$-agonist [LABA]), and 23.0\% LABA/ICS (Table 1).

The median time on study treatment after the index exacerbation did not differ according to the treatment received for the index exacerbation (521-551 days) except for patients who were hospitalized; these patients spent a shorter time on treatment (412 days) following the initial event (Table 2).

\section{Index exacerbation(s) Nonhospitalized exacerbations}

The frequency of subsequent exacerbations varied by treatment received for the index exacerbation. The annual exacerbation rate for patients with antibiotics only (0.79) was lower than that for those treated with systemic corticosteroids alone $(0.95)$ or in combination with antibiotics (1.04; Table 2). Accordingly, the time to subsequent exacerbations was shorter (greater risk) for patients treated with systemic corticosteroids only (HR: 1.21 [95\% CI: 1.09-1.34]) or antibiotics and systemic corticosteroids (HR: 1.33 [95\% CI: $1.24-1.43]$ ) versus those treated with antibiotics only (Figure 1; Table S1).

When looking at exacerbations occurring within 60 days of the end of the index exacerbation, $14.7 \%$ of patients treated with systemic corticosteroids only and $16.3 \%$ with antibiotics and corticosteroids experienced another exacerbation versus $11.6 \%$ and $12.2 \%$ for those whose initial event required hospitalization or antibiotics only (Table 3). Kaplan-Meier analysis showed that patients who received antibiotics and systemic corticosteroids for their index exacerbation had the highest estimated probability of a subsequent exacerbation (Figure 2A).

\section{Exacerbations requiring hospitalization}

Patients who experienced severe index exacerbation (hospitalized) had a higher annual rate of subsequent hospitalization due to COPD than patients who experienced a less severe initial event (Table 2). Consequently, patients who experienced a severe index exacerbation had a higher risk of a subsequent hospitalized exacerbation than patients with a moderate index exacerbation who received antibiotics only (HR: 4.31 [95\% CI: 3.76-4.95]; Figure 1; Table S1). Patients who required hospitalization for their initial event were also at higher risk of a subsequent severe exacerbation within 60 days than those who received antibiotics, corticosteroids, or a combination thereof.

Patients who initially required hospitalization had a similar rate of subsequent exacerbation to those treated with 
Table I Patient demographics and baseline characteristics

\begin{tabular}{|c|c|c|c|c|c|}
\hline \multirow[t]{3}{*}{ Characteristic } & \multirow{3}{*}{$\begin{array}{l}\text { Total study } \\
\text { population, } \\
\mathrm{N}=8,06 \mathrm{I}\end{array}$} & \multicolumn{4}{|c|}{ Index on-treatment exacerbation } \\
\hline & & \multicolumn{3}{|l|}{ Moderate } & \multirow{2}{*}{$\begin{array}{l}\text { Severe } \\
\text { (requiring } \\
\text { hospitalization), } \\
N=1,490\end{array}$} \\
\hline & & $\begin{array}{l}\text { Treated with } \\
\text { antibiotics } \\
\text { only, } \\
\mathrm{N}=3,080\end{array}$ & $\begin{array}{l}\text { Treated with } \\
\text { systemic } \\
\text { corticosteroids } \\
\text { only, } \mathbf{N}=\mathbf{8 2} \text { I }\end{array}$ & $\begin{array}{l}\text { Treated with } \\
\text { antibiotics } \\
\text { and systemic } \\
\text { corticosteroids, } \\
\mathrm{N}=2,670\end{array}$ & \\
\hline Males, n (\%) & $5,463(67.8)$ & $2,091(67.9)$ & $564(68.7)$ & $\mathrm{I}, 667(62.4)$ & $\mathrm{I}, 14 \mathrm{I}(76.6)$ \\
\hline Age, years, mean (SD) & $65.2(9.0)$ & $64.7(8.9)$ & $65.5(9.2)$ & $65.2(9.0)$ & $66.2(9.0)$ \\
\hline $\mathrm{BMI}, \mathrm{kg} / \mathrm{m}^{2}$, mean $(\mathrm{SD})$ & $26.1(5.8)$ & $26.4(5.6)$ & $25.9(5.7)$ & $26.2(5.8)$ & $25.4(6.1)$ \\
\hline \multicolumn{6}{|l|}{ BMI category, n (\%) } \\
\hline$<18.5 \mathrm{~kg} / \mathrm{m}^{2}$ & $564(7.0)$ & $178(5.8)$ & $52(6.3)$ & $182(6.8)$ & $152(10.2)$ \\
\hline 18.5 to $<25 \mathrm{~kg} / \mathrm{m}^{2}$ & $3,175(39.4)$ & $1,135(36.9)$ & $352(42.9)$ & $\mathrm{I}, 020(38.2)$ & $668(44.8)$ \\
\hline 25 to $<30 \mathrm{~kg} / \mathrm{m}^{2}$ & $2,537(31.5)$ & $1,066(34.6)$ & $250(30.5)$ & $853(31.9)$ & $368(24.7)$ \\
\hline$\geq 30 \mathrm{~kg} / \mathrm{m}^{2}$ & $1,785(22.1)$ & $70 \mathrm{I}(22.8)$ & $167(20.3)$ & $615(23.0)$ & $302(20.3)$ \\
\hline \multicolumn{6}{|l|}{ Region, n (\%) } \\
\hline Euro/Africa/Aus/NZ & $4,342(53.9)$ & I,842 (59.8) & $427(52.0)$ & $\mathrm{I}, 284(48.1)$ & $789(53.0)$ \\
\hline Latin America & $539(6.7)$ & $168(5.5)$ & $82(10.0)$ & $230(8.6)$ & $59(4.0)$ \\
\hline North America & $2,227(27.6)$ & $721(23.4)$ & $217(26.4)$ & $958(35.9)$ & $331(22.2)$ \\
\hline Asia & $953(11.8)$ & $349(11.3)$ & $95(11.6)$ & $198(7.4)$ & $311(20.9)$ \\
\hline Duration of COPD, years, mean (SD) & $7.9(6.2)$ & $7.7(6.3)$ & $7.9(6.1)$ & $8.1(6.2)$ & $7.7(6.0)$ \\
\hline Smoking history, pack-years, mean (SD) ${ }^{\mathrm{a}}$ & $44.7(25.3)$ & $43.0(23.7)$ & $45.0(26.0)$ & $46.1(26.2)$ & $45.2(26.3)$ \\
\hline $\begin{array}{l}\text { No of COPD episodes treated in the last year, } \\
\text { mean (SD) }\end{array}$ & $1.0(1.3)$ & $1.0(1.3)$ & $0.9(1.3)$ & I.I (I.4) & $1.1(1.3)$ \\
\hline \multicolumn{6}{|l|}{ No of COPD episodes treated in the last year, $n(\%)^{a}$} \\
\hline 0 & $3,56 \mathrm{I}(44.2)$ & $\mathrm{I}, 409(45.7)$ & $407(49.6)$ & $\mathrm{I}, 172(43.9)$ & $573(38.5)$ \\
\hline 1 & $2,437(30.2)$ & $934(30.3)$ & $229(27.9)$ & $772(28.9)$ & $502(33.7)$ \\
\hline 2 & $\mathrm{I}, \mathrm{I} 86(14.7)$ & $435(14.1)$ & $109(13.3)$ & $404(15.1)$ & $238(16.0)$ \\
\hline 3 & $512(6.4)$ & $174(5.6)$ & $43(5.2)$ & $185(6.9)$ & $110(7.4)$ \\
\hline 4 & $194(2.4)$ & $74(2.4)$ & $16(1.9)$ & $73(2.7)$ & $31(2.1)$ \\
\hline$\geq 5$ & $164(2.0)$ & $51(1.7)$ & $16(1.9)$ & $62(2.3)$ & $35(2.3)$ \\
\hline \multicolumn{6}{|l|}{ Postbronchodilator spirometry, mean (SD) ${ }^{\mathrm{a}}$} \\
\hline $\mathrm{FEV}_{1}, \mathrm{~L}$ & I.265 (0.459) & $\mathrm{I} .354(0.469)$ & $\mathrm{I} .248(0.450)$ & $\mathrm{I} .249(0.446)$ & I.I I9 (0.420) \\
\hline $\mathrm{FEV}_{1}, \%$ predicted & $46.4(13.9)$ & $48.9(13.7)$ & $45.7(13.8)$ & $46.3(13.6)$ & $41.7(13.7)$ \\
\hline FVC, L & $2.649(0.832)$ & $2.758(0.842)$ & $2.634(0.854)$ & $2.624(0.8 \mid 2)$ & $2.477(0.800)$ \\
\hline Ratio of $\mathrm{FEV}$, to FVC & $0.484(0.115)$ & $0.497(0.113)$ & $0.482(0.121)$ & $0.482(0.115)$ & $0.459(0.114)$ \\
\hline \multicolumn{6}{|l|}{ GOLD stage, $\mathrm{n}(\%)^{\mathrm{a}}$} \\
\hline $\mathrm{I} / \mathrm{II}$ & $3,410(42.3)$ & $\mathrm{I}, 543(50.1)$ & $327(39.8)$ & $\mathrm{I}, 097(4 \mathrm{I} . \mathrm{I})$ & $443(29.7)$ \\
\hline III & $3,478(43.1)$ & $1,205(39.1)$ & $359(43.7)$ & $\mathrm{I}, 20 \mathrm{I}(45.0)$ & $713(47.9)$ \\
\hline IV & $\mathrm{I}, 074(13.3)$ & $292(9.5)$ & $123(15.0)$ & $337(12.6)$ & $322(21.6)$ \\
\hline Cardiac history & $2,17 \mid(26.9)$ & $825(26.8)$ & $184(22.4)$ & $677(25.4)$ & $485(32.6)$ \\
\hline Previous cardiac arrhythmia, $\mathrm{n}(\%)$ & $909(11.3)$ & $348(11.3)$ & $83(10.1)$ & $298(11.2)$ & $180(12.1)$ \\
\hline Previous MI, n (\%) & $515(6.4)$ & $181(5.9)$ & $44(5.4)$ & $181(6.8)$ & $109(7.3)$ \\
\hline Previous stroke, n (\%) & $177(2.2)$ & $64(2.1)$ & $18(2.2)$ & $53(2.0)$ & $42(2.8)$ \\
\hline Previous IHD or CAD, $n(\%)$ & $\mathrm{I}, 225(\mathrm{I} 5.2)$ & $483(15.7)$ & $106(12.9)$ & $354(13.3)$ & $282(18.9)$ \\
\hline \multicolumn{6}{|l|}{ History of heart failure, $n(\%)^{\mathrm{a}}$} \\
\hline None & $7,453(92.5)$ & $2,856(92.7)$ & $779(94.9)$ & $2,530(94.8)$ & $1,288(86.4)$ \\
\hline Class I & $222(2.8)$ & $82(2.7)$ & $13(1.6)$ & $57(2.1)$ & $70(4.7)$ \\
\hline Class II & $321(4.0)$ & $120(3.9)$ & $25(3.0)$ & $65(2.4)$ & III (7.4) \\
\hline Class III & $55(0.7)$ & $17(0.6)$ & $3(0.4)$ & $16(0.6)$ & $19(1.3)$ \\
\hline Class IV & $3(0.0)$ & I $(0.0)$ & $\mathrm{I}(0.1)$ & $0(0.0)$ & $I(0.1)$ \\
\hline Taking CV medication, $\mathrm{n}(\%)$ & $4,204(52.2)$ & $1,610(52.3)$ & $421(51.3)$ & $\mathrm{I}, 416(53.0)$ & $757(50.8)$ \\
\hline Taking respiratory medication, $\mathrm{n}(\%)^{\mathrm{a}}$ & $7,620(94.5)$ & $2,853(92.6)$ & $793(96.6)$ & $2,561(95.9)$ & $1,413(94.8)$ \\
\hline ICS only & $438(5.4)$ & $134(4.4)$ & $52(6.3)$ & $159(6.0)$ & $93(6.2)$ \\
\hline LABA only & $355(4.4)$ & $159(5.2)$ & $34(4.1)$ & $104(3.9)$ & $58(3.9)$ \\
\hline LAMA only & $74 \mid(9.2)$ & $323(10.5)$ & $79(9.6)$ & $216(8.1)$ & $123(8.3)$ \\
\hline LABA+ICS only & $1,852(23.0)$ & $693(22.5)$ & $185(22.5)$ & $620(23.2)$ & $354(23.8)$ \\
\hline ICS+LABA+LAMA & $2,924(36.3)$ & I,04I (33.8) & $292(35.6)$ & I,038 (38.9) & $553(37.1)$ \\
\hline
\end{tabular}

Notes: Percentages shown are "column" percentages. aPatients with missing data were excluded.

Abbreviations: Aus, Australia; BMI, body mass index; CAD, coronary artery disease; CV, cardiovascular; Euro, Europe; GOLD, Global Initiative for Chronic Obstructive Lung Disease; ICS, inhaled corticosteroid; IHD, ischemic heart disease; LABA, long-acting $\beta_{2}$-agonist; LAMA, long-acting muscarinic antagonist; MI, myocardial infarction; NZ, New Zealand. 
Table 2 Median time to, and annual rate of event by, treatment for index moderate or severe exacerbation, adjusted for inhaled corticosteroid use and exacerbation history

\begin{tabular}{|c|c|c|c|c|}
\hline \multirow[t]{3}{*}{ Subsequent event } & \multicolumn{4}{|c|}{ Index on-treatment exacerbation } \\
\hline & \multicolumn{3}{|l|}{ Moderate } & \multirow{2}{*}{$\begin{array}{l}\text { Severe } \\
\text { (requiring } \\
\text { hospitalization) }\end{array}$} \\
\hline & $\begin{array}{l}\text { Treated with } \\
\text { antibiotics } \\
\text { only }\end{array}$ & $\begin{array}{l}\text { Treated with } \\
\text { systemic } \\
\text { corticosteroids } \\
\text { only }\end{array}$ & $\begin{array}{l}\text { Treated with } \\
\text { antibiotics } \\
\text { and systemic } \\
\text { corticosteroids }\end{array}$ & \\
\hline Duration of index exacerbation, days (SD) & $15.6(20.1)$ & $19.2(28.5)$ & $21.1(33.7)$ & $19.6(23.2)$ \\
\hline $\begin{array}{l}\text { Total time on study treatment after the start of index } \\
\text { exacerbation, days, median }\end{array}$ & 551 & 521 & 550 & 412 \\
\hline No of patients in the exacerbation analysis & $\mathrm{N}=3,028$ & $\mathrm{~N}=791$ & $N=2,577$ & $\mathrm{~N}=1,359$ \\
\hline Moderate to severe exacerbation, $\mathrm{n}(\%)$ & $|, 63|(53.9)$ & $450(56.9)$ & $1,610(62.5)$ & $700(51.5)$ \\
\hline Time to subsequent exacerbation, days, median (QI, Q3) & $376(128,902)$ & $282(111,777)$ & $261(92,645)$ & $34 I(124,804)$ \\
\hline Annual rate $(95 \% \mathrm{Cl})$ & $0.79(0.75-0.83)$ & $0.95(0.88-1.03)$ & $1.04(0.99-1.09)$ & $0.86(0.80-0.92)$ \\
\hline Severe exacerbation, $\mathrm{n}(\%)$ & $355(11.7)$ & $135(17.1)$ & $478(18.5)$ & $483(35.5)$ \\
\hline Annual rate $(95 \% \mathrm{Cl})$ & $0.10(0.09-0.11)$ & $0.16(0.13-0.19)$ & $0.17(0.16-0.19)$ & $0.46(0.4 \mid-0.52)$ \\
\hline $\begin{array}{l}\text { No of patients in the hospitalization, death, and } \\
\text { discontinuation analysis }\end{array}$ & $\mathrm{N}=3,070$ & $\mathrm{~N}=820$ & $\mathrm{~N}=2,660$ & $\mathrm{~N}=1,486$ \\
\hline Hospitalization (all-cause), n (\%) & $772(25.1)$ & $242(29.5)$ & $838(31.5)$ & $758(51.0)$ \\
\hline Annual rate $(95 \% \mathrm{Cl})$ & $0.28(0.26-0.30)$ & $0.36(0.32-0.42)$ & $0.39(0.36-0.42)$ & $0.98(0.89-1.07)$ \\
\hline Death (all-cause), n (\%) & $164(5.3)$ & $64(7.8)$ & $209(7.9)$ & $240(16.2)$ \\
\hline Death due to COPD, n (\%) & $45(1.5)$ & $26(3.2)$ & $85(3.2)$ & $106(7.1)$ \\
\hline Discontinuation, n (\%) & $435(14.2)$ & $162(19.8)$ & $509(19.1)$ & $434(29.2)$ \\
\hline
\end{tabular}

Notes: Percentages shown are "column" percentages. Time at risk of subsequent exacerbation started the day after the end of the first exacerbation and ended at treatment stop. Time at risk of subsequent hospitalization, discontinuation, or death started the day after the start of the first exacerbation and ended at treatment stop +30 days (or death) (for hospitalization), treatment stop (for discontinuation), or at last known date alive or death (for death).

Abbreviation: Q, quartile.

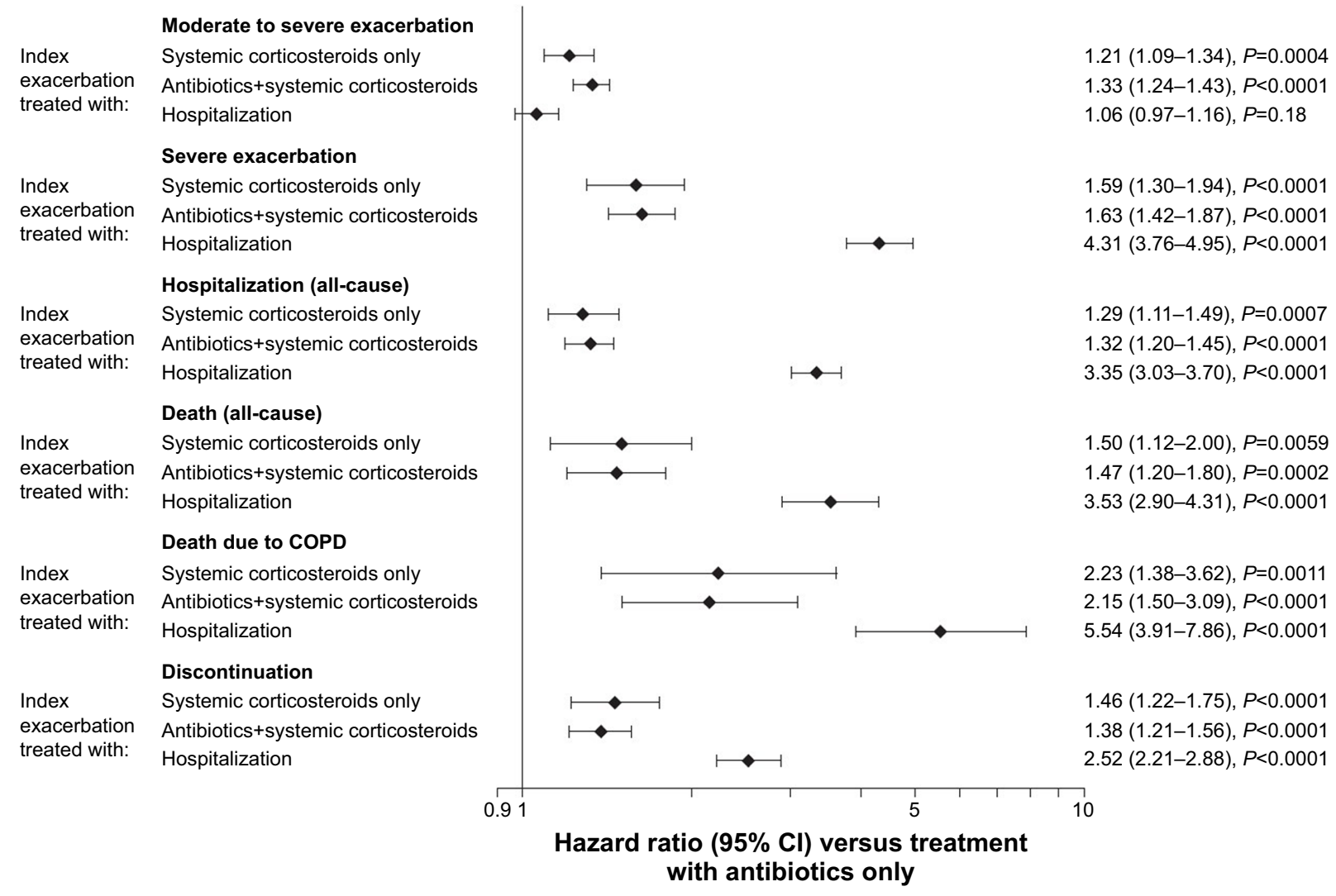

Figure I Forest plot showing the risk of subsequent event by treatment for index exacerbation versus antibiotics only.

Notes: Hazard ratios for the time at risk of subsequent exacerbation were adjusted for inhaled corticosteroid use at baseline and exacerbation in the year prior to study. Time at risk of subsequent exacerbation started the day after the end of the first exacerbation and ended at treatment stop. Time at risk of subsequent hospitalization, discontinuation, or death started the day after the start of the first exacerbation and ended at treatment stop +30 days (or death) (for hospitalization), treatment stop (for discontinuation), or at last known date alive or death (for death). 
Table 3 Logistic regression analysis: relationship between index exacerbation severity and subsequent exacerbation, hospitalization, or death within 60 days following first on-treatment exacerbation

\begin{tabular}{|c|c|c|c|c|}
\hline \multirow[t]{3}{*}{ Subsequent event } & \multicolumn{4}{|c|}{ Index on-treatment exacerbation } \\
\hline & \multicolumn{3}{|l|}{ Moderate } & \multirow{2}{*}{$\begin{array}{l}\text { Severe } \\
\text { (requiring } \\
\text { hospitalization) }\end{array}$} \\
\hline & $\begin{array}{l}\text { Treated with } \\
\text { antibiotics } \\
\text { only }\end{array}$ & $\begin{array}{l}\text { Treated with } \\
\text { systemic } \\
\text { corticosteroids } \\
\text { only }\end{array}$ & $\begin{array}{l}\text { Treated with } \\
\text { antibiotics } \\
\text { and systemic } \\
\text { corticosteroids }\end{array}$ & \\
\hline $\begin{array}{l}\text { No of patients in the exacerbation } \\
\text { analysis }\end{array}$ & $\mathrm{N}=3,028$ & $N=791$ & $\mathrm{~N}=2,577$ & $\mathrm{~N}=1,359$ \\
\hline Moderate to severe exacerbation, $\mathrm{n}(\%)$ & $369(12.2)$ & $116(14.7)$ & $420(16.3)$ & I58 (I I.6) \\
\hline OR $(95 \% \mathrm{Cl})$ & - & $1.26(1.00-1.57)$ & $1.37(1.18-1.59)$ & $0.90(0.74-1.10)$ \\
\hline Severe exacerbation, $\mathrm{n}(\%)$ & $49(1.6)$ & $22(2.8)$ & $71(2.8)$ & $106(7.8)$ \\
\hline OR $(95 \% \mathrm{Cl})$ & - & $1.75(1.03-2.87)$ & $1.67(1.16-2.42)$ & $4.91(3.49-6.99)$ \\
\hline $\begin{array}{l}\text { No of patients in the hospitalization, } \\
\text { death, and discontinuation analysis }\end{array}$ & $\mathrm{N}=3,070$ & $\mathrm{~N}=820$ & $N=2,660$ & $\mathrm{~N}=1,486$ \\
\hline Hospitalization (all-cause), n (\%) & $107(3.5)$ & $40(4.9)$ & $135(5.1)$ & $283(19.0)$ \\
\hline OR $(95 \% \mathrm{Cl})$ & - & $1.41(0.96-2.03)$ & $1.46(1.13-1.89)$ & $6.44(5.12-8.15)$ \\
\hline Death (all-cause), n (\%) & $10(0.3)$ & $7(0.9)$ & $21(0.8)$ & $61(4.1)$ \\
\hline OR $(95 \% \mathrm{Cl})$ & - & $2.72(0.98-7.10)$ & $2.47(1.19-5.49)$ & $12.97(6.93-27.02)$ \\
\hline Discontinuation, n (\%) & $66(2.2)$ & $40(4.9)$ & $102(3.8)$ & $169(11.4)$ \\
\hline OR $(95 \% \mathrm{Cl})$ & - & $2.33(1.55-3.46)$ & I.82 (I.33-2.50) & $5.85(4.39-7.88)$ \\
\hline
\end{tabular}

Notes: Percentages shown are "column" percentages. OR was calculated for subsequent events within 60 days started either after the onset of the first exacerbation (not leading to discontinuation) (for subsequent hospitalization, death, and discontinuation) or after the end of the first exacerbation (not leading to discontinuation) (for subsequent exacerbation). OR was calculated for patients treated with antibiotics only and adjusted for inhaled corticosteroid use at baseline and exacerbation in the year prior to study.

Abbreviation: OR, odds ratio.

antibiotics only (HR: 1.06 [95\% CI: 0.97-1.16]) and a lower risk of subsequent exacerbation versus patients treated with antibiotics and systemic corticosteroids (HR: 1.25 [95\% CI: 1.15-1.37]; Table S1).

\section{Subsequent hospitalization (all-cause)}

Annual rates for (all-cause) hospitalizations followed the same pattern as those observed for hospitalizations due to $\mathrm{COPD}$, and these were lowest in patients who were treated

A

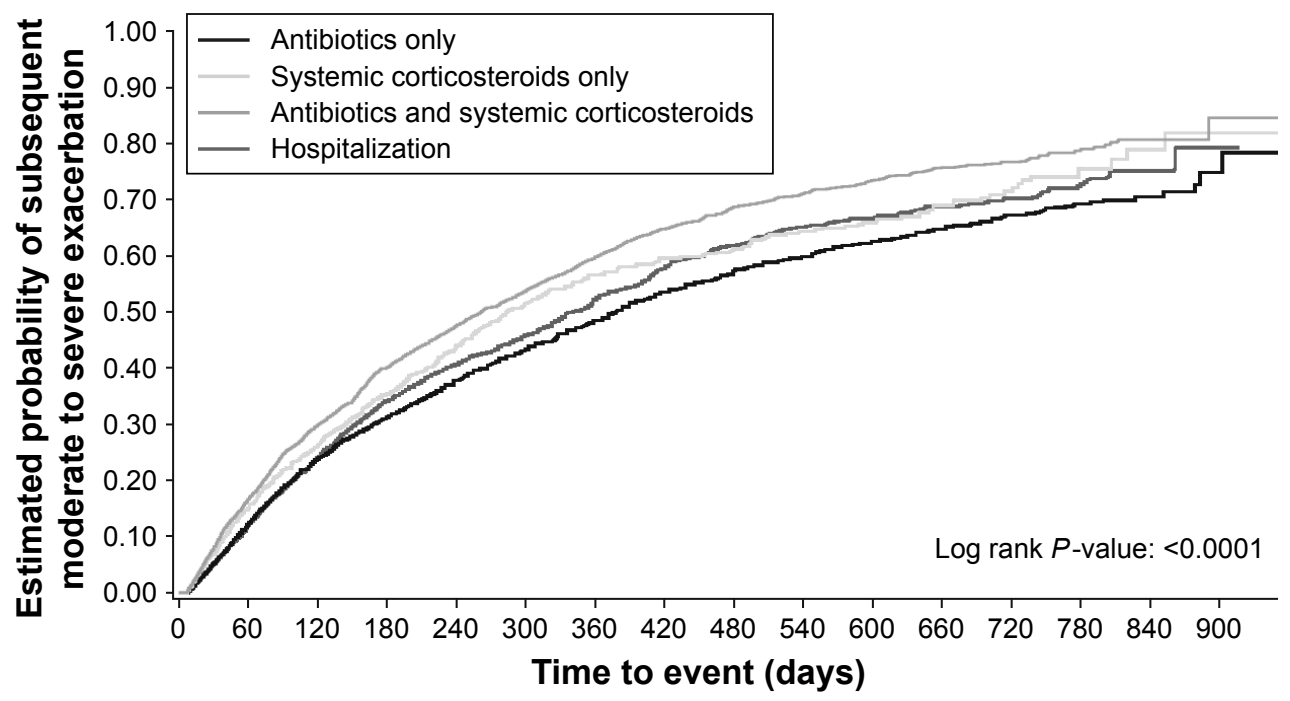

Patients at risk Antibiotics only Systemic corticosteroids only Antibiotics and systemic corticosteroids Hospitalization

$\begin{array}{llllllllllllllll}3,038 & 2,538 & 2,093 & 1,808 & 1,584 & 1,356 & 1,107 & 901 & 721 & 584 & 477 & 388 & 248 & 120 & 38 & 7 \\ 792 & 639 & 518 & 425 & 353 & 283 & 229 & 185 & 157 & 119 & 99 & 72 & 46 & 17 & 8 & 4 \\ 2,582 & 2,043 & 1,632 & 1,314 & 1,104 & 913 & 731 & 564 & 437 & 334 & 265 & 204 & 127 & 63 & 23 & 3 \\ 1,362 & 1,090 & 874 & 715 & 610 & 512 & 381 & 284 & 224 & 168 & 134 & 106 & 63 & 32 & 7 & 1\end{array}$

Figure 2 (Continued) 


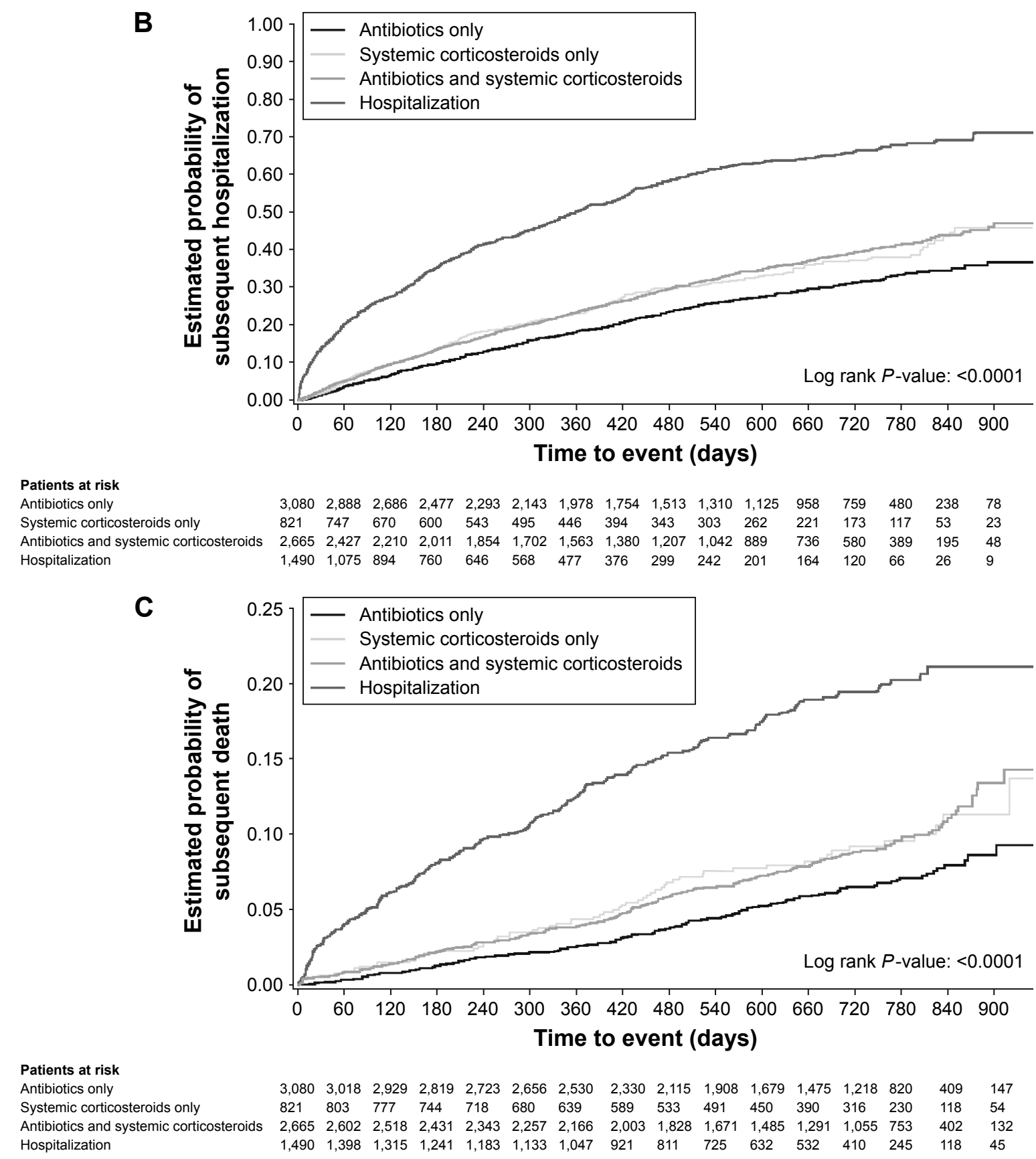

Figure 2 Time to (A) subsequent exacerbation, (B) hospitalization (all-cause) or (C) death (all-cause), by severity of first exacerbation on treatment.

with antibiotics only and highest in patients initially hospitalized for their index exacerbation (Table 2). This was reflected in a shorter time to (greater risk of) subsequent hospitalization for patients who were initially hospitalized versus antibiotics only (HR: 3.35 [95\% CI: 3.03-3.70]) compared with patients who received systemic corticosteroids (HR: 1.29 [95\% CI: 1.11-1.49]), or antibiotics and corticosteroids (HR: 1.32 [95\% CI: 1.20-1.45]; Figure 1; Table S1). Similarly, patients hospitalized for their index exacerbation were more than four times as likely to experience an adverse event requiring hospitalization within 60 days of the onset of the index exacerbation as patients who experienced a less severe initial event (Table 3). Kaplan-Meier analysis showed that initially hospitalized patients were at the highest risk of a subsequent hospitalization compared with patients who were treated with antibiotics and/or steroids (Figure 2B).

\section{Subsequent death (all-cause)}

The percentage of patients who died was twice as high for patients whose index exacerbation required hospitalization 
than for those with less severe index exacerbations. Therefore, hospitalization for index exacerbation was an important risk factor for subsequent death (all-cause; HR: 3.53 [95\% CI: 2.90-4.31]), in particular for death due to COPD (HR: 5.54 [95\% CI: 3.91-7.86]; Figure 1; Table S1) versus patients treated with antibiotics only. Patients who received systemic corticosteroids only (HR: 1.50 [95\% CI: 1.12-2.00]) or in combination with antibiotics (HR: 1.47 [95\% CI: 1.20-1.80]) were nevertheless also at a higher risk of subsequent allcause death compared with patients treated with antibiotics only. In the 60 days following the onset of the initial event, patients initially hospitalized were four times more likely to die than patients who received antibiotics only, systemic corticosteroids only, or the combination (Table 3). These results were confirmed by Kaplan-Meier analysis in which the estimated probability of subsequent death was highest in patients initially hospitalized (Figure 2C).

\section{Subsequent discontinuation}

A total of 1,540 patients (19.1\%) discontinued prematurely from the study (for any reason including death and at any time) following the onset of their index exacerbation. Patients who were hospitalized (severe exacerbation) were most likely to discontinue $(29.2 \%)$; patients receiving antibiotics only discontinued the least (14.2\%; Table 2). The highest risk of premature discontinuation versus patients treated with antibiotics only was observed in patients who initially required hospitalization (HR: 2.52 [95\% CI: 2.21-2.88]), followed by patients who were treated with systemic corticosteroids (HR: 1.46 [95\% CI: 1.22-1.75]), or antibiotics and corticosteroids (HR: 1.38 [95\% CI: 1.21-1.56]; Figure 1; Table S1). Within the first 60 days of onset of the index exacerbation, the increased risk of discontinuation in patients initially hospitalized (11.4\%) was more pronounced than in those treated with corticosteroids only $(4.9 \%)$, with antibiotics and corticosteroids $(3.8 \%)$, or with antibiotics only $(2.2 \%)$ for their index exacerbation (Table 3).

\section{Discussion}

In this retrospective analysis of the TIOSPIR dataset, we found that patients with exacerbations who were treated with systemic corticosteroids alone, or together with antibiotics, exacerbated sooner and more frequently than those treated with antibiotics alone, and that an initial hospitalization was a powerful predictor of subsequent hospitalization, mortality, and premature discontinuation. These findings held true even after adjustment for prior ICS use and exacerbation history. While we do not suggest that these findings indicate that lesser treatment benefits the patient, we do believe that the information is of clinical interest both to the analysis of COPD trials and to future clinical management.

Time to first COPD exacerbation in the TIOSPIR study was a prespecified outcome, but no specific instructions were given about how exacerbations should be managed. Despite this, and the many healthcare systems that contributed patients to this study, there were clear differences in the treatments given for the first recorded exacerbation (index exacerbation) after randomization. It remains unclear, however, whether geographic and healthcare settings may also influence exacerbation outcomes (eg, in Asia, more patients were hospitalized for their index exacerbation, whereas patients in North America were more likely to receive a combination of antibiotics and steroids). On an individual level, the reasons for hospitalization of patients can also vary.

Nonetheless, using a healthcare utilization definition to distinguish different exacerbation groups, we saw little difference between patient groups in many baseline variables such as age, smoking history, and BMI. There were differences in the degree of spirometric impairment among those receiving antibiotics, those for whom systemic corticosteroids were added, and those who were hospitalized for their first observed exacerbation. Although such differences are reflected in the distribution of GOLD stages among treatment groups, GOLD stage per se did not clearly discriminate between treatment choices. Thus, $27.2 \%$ of GOLD Stage IV patients received antibiotics alone, while almost $30 \%$ of hospitalized patients were in the GOLD Stage I/II subset. This confirms earlier observations about the imperfect relationship between spirometric impairment and hospitalization in COPD studies. ${ }^{15}$ There were no consistent differences in either the reported presence of cardiac disease or cardiac medication between treatment groups, suggesting that, in this population, COPD hospitalization was likely driven by respiratory rather than comorbid cardiac factors.

Outcomes for patients who received systemic corticosteroids, whether as monotherapy or combined with antibiotics, differed from those for patients treated with antibiotics alone. Corticosteroid-treated patients experienced more exacerbations that occurred sooner after the index exacerbation and were more likely to require hospitalization or be followed by death than was the case in the antibiotic monotherapy group. However, the addition of antibiotics to the corticosteroid was not associated with differences in outcomes, suggesting that the decision to prescribe corticosteroids was the marker for poorer outcomes. These between-group differences are unlikely to reflect differences in baseline severity of COPD 
and were evident when the analysis was restricted to the 60-day risk period following the index exacerbation event. The decision to offer a different treatment may reflect the clinical perception of differences between the events, eg, more "severe" episodes require systemic corticosteroid therapy. Clearly, the treatment decision is also influenced by customary practices of care. However, some preliminary data suggest that patients treated with corticosteroids are more likely to report breathlessness as their dominant exacerbation symptom, whereas patients who receive antibiotics complain mainly of cough and sputum production. ${ }^{16}$ It is not possible to determine, however, whether some patients were treated inappropriately and whether this may have affected outcomes; for instance, oral corticosteroids are associated with worse outcomes and earlier relapse when used to treat infective exacerbations. ${ }^{17}$ Further studies to explore differences in exacerbation treatment choice are warranted.

Hospitalization for COPD is a more serious outcome and carries a high risk of subsequent death, as noted previously. ${ }^{18-21}$ This increased mortality risk was seen within 60 days of the index event and increased further during the following year. The risk of death compared with that in nonhospitalized patients was broadly similar in the 60-day and 12-month follow-up periods, suggesting that in general the hospitalized patients were intrinsically more likely to die rather than the insult associated with hospitalization being especially severe. Hospitalized patients were less likely to receive antibiotics and/or corticosteroids as outpatients to treat their next exacerbation, which could have been because either they were much more likely to be hospitalized on the next occasion and/or they were more likely to withdraw from the study, or to have died before another event could occur. These data confirm that hospitalized patients pursue a different natural history than nonhospitalized patients, as is suggested from database studies; ${ }^{21}$ this has been acknowledged in the current GOLD classification of risk severity. ${ }^{14}$

Our analysis has a number of strengths, but also has some limitations. TIOSPIR was a large but relatively uncomplicated clinical trial with an almost complete ascertainment of mortality, irrespective of study withdrawal. We adjudicated the cause of death independently from the trial steering group, but did not repeat this exercise for exacerbations, a technically daunting process that is recommended by some authorities. ${ }^{22}$ Nonetheless, we regularly monitored whether exacerbations had occurred, how they had been treated, and their frequency. The size of our study allowed us to distinguish differences in exacerbation events between patients treated with antibiotics and patients receiving systemic corticosteroids alone-groups that are often too small to generate separate analyses in other studies. ${ }^{11}$ All participants received tiotropium, and those initially taking LABA and/or ICS - agents known to prevent exacerbations ${ }^{23,24}$ - continued these drugs, with $\sim 60 \%$ of participants receiving triple therapy during the study. However, we found no difference between the exacerbationdefined treatment groups in maintenance therapy used, suggesting that the therapy for the event when it occurred was not determined by the treatment already taken regularly to manage their COPD. Finally, our data cannot exclude the possibility that therapy with systemic corticosteroids led to more frequent exacerbations later, resulting from some as yet unidentified deleterious effect of this therapy. Although this seems unlikely, further studies to elucidate the long-term effect of the initial therapy selected appear to be justified.

We did not specify how an exacerbation should be managed, but suggested that the clinician should follow their usual practice. This could be interpreted as a study weakness; however, we suggest instead that the results are consequently more reflective of the real-life clinical situation, providing key insights into this perspective. Had we been able to monitor patients using diary cards, it is likely that we would have identified even more events ${ }^{25}$ and would have also been able to study the time course of recovery with treatment, an important consideration when assessing the risk of relapse. ${ }^{26}$ Nevertheless, our data relate to clinical circumstances under which this more detailed information was not available, and therefore, our findings may be more directly relevant to understanding exacerbation management during routine clinical practice.

Our data have wide implications. In patients receiving recommended treatments known to prevent COPD exacerbations, episodes that required systemic corticosteroid treatment with or without antibiotics differed from those that were treated with antibiotics only. The same is true for exacerbations that led to hospitalizations. Hence, therapies that reduce the number of corticosteroid-treated episodes (with or without antibiotics) and hospitalizations may be particularly impactful. ${ }^{27,28}$ The considerable predictive value of our initial hospitalization data suggests that treatment trials where cost-effectiveness is a key outcome should recruit such patients, as it is in these studies that signals are most readily seen, as was the case with the Roflumilast and Exacerbations in patients receiving Appropriate Combination Therapy (REACT) study. ${ }^{29}$ Finally, clinicians should be aware that the way they choose to treat exacerbations identifies patients who are at different risk of future hospitalization and death. Greater awareness of this fact could identify patients at the 
greatest risk of future problems and ensure they are treated and monitored accordingly.

\section{Acknowledgments}

Writing assistance was provided by Sarah J Petit and Jennifer C Fuchs of PAREXEL and Claire Scofield of MediTech Media, and was funded by Boehringer Ingelheim.

\section{Author contributions}

All authors confirm involvement in the conception, hypotheses delineation, and design of the study; acquisition, analysis, or interpretation of the data; writing or substantial involvement in the article's revision prior to submission; and agree to be accountable for all aspects of the work.

\section{Disclosure}

Outside of the submitted work, PMAC reports receiving research grants from GlaxoSmithKline and Takeda; personal fees from AstraZeneca, Boehringer Ingelheim, GlaxoSmithKline, Novartis, and Takeda; and nonfinancial support from Boehringer Ingelheim. ARA reports receiving consulting fees from AstraZeneca, Boehringer Ingelheim, GlaxoSmithKline, and Novartis; and grant support from GlaxoSmithKline. DD reports receiving consulting fees, lecture fees, and payment for the development of educational activities from Boehringer Ingelheim, Chiesi, Dey Pharma, Novartis, Nycomed, and Pfizer. RAW reports receiving consulting fees from AstraZeneca, Boehringer Ingelheim, Bristol-Myers Squibb, ContraFect, GlaxoSmithKline, Janssen, Mylan, Novartis, Pfizer, Pulmonx, Roche, Spiration, Sunovion, Teva, Theravance, Verona, and Vertex; and grant support from Boehringer Ingelheim, GlaxoSmithKline, and Pearl Therapeutics. AM and NM are employees of Boehringer Ingelheim. The authors report no other conflicts of interest in this work.

\section{References}

1. Davies L, Angus RM, Calverley PM. Oral corticosteroids in patients admitted to hospital with exacerbations of chronic obstructive pulmonary disease: a prospective randomised controlled trial. Lancet. 1999;354(9177):456-460.

2. Niewoehner DE, Erbland ML, Deupree RH, et al. Effect of systemic glucocorticoids on exacerbations of chronic obstructive pulmonary disease. Department of Veterans Affairs Cooperative Study Group. N Engl J Med. 1999;340(25):1941-1947.

3. Aaron SD, Vandemheen KL, Hebert P, et al. Outpatient oral prednisone after emergency treatment of chronic obstructive pulmonary disease. N Engl J Med. 2003;348(26):2618-2625.

4. Leuppi JD, Schuetz P, Bingisser R, et al. Short-term vs. conventional glucocorticoid therapy in acute exacerbations of chronic obstructive pulmonary disease: the REDUCE randomized clinical trial. JAMA. 2013;309(21):2223-2231.
5. Anthonisen NR, Manfreda J, Warren CP, Hershfield ES, Harding GK, Nelson NA. Antibiotic therapy in exacerbations of chronic obstructive pulmonary disease. Ann Intern Med. 1987;106(2):196-204.

6. Daniels JM, Snijders D, de Graaff CS, Vlaspolder F, Jansen HM, Boersma WG. Antibiotics in addition to systemic corticosteroids for acute exacerbations of chronic obstructive pulmonary disease. $\mathrm{Am} \mathrm{J}$ Respir Crit Care Med. 2010;181(2):150-157.

7. Roede BM, Bresser P, Prins JM, Schellevis F, Verheij TJ, Bindels PJ. Reduced risk of next exacerbation and mortality associated with antibiotic use in COPD. Eur Respir J. 2009;33(2):282-288.

8. Rothberg MB, Pekow PS, Lahti M, Brody O, Skiest DJ, Lindenauer PK. Antibiotic therapy and treatment failure in patients hospitalized for acute exacerbations of chronic obstructive pulmonary disease. JAMA. 2010;303(20):2035-2042

9. Mullerova H, Maselli DJ, Locantore N, et al. Hospitalized exacerbations of COPD: risk factors and outcomes in the ECLIPSE cohort. Chest. 2015;147(4):999-1007.

10. Dransfield MT, Bourbeau J, Jones PW, et al. Once-daily inhaled fluticasone furoate and vilanterol versus vilanterol only for prevention of exacerbations of COPD: two replicate double-blind, parallel-group, randomised controlled trials. Lancet Respir Med. 2013;1(3):210-223.

11. Wedzicha JA, Calverley PM, Seemungal TA, et al. The prevention of chronic obstructive pulmonary disease exacerbations by salmeterol/fluticasone propionate or tiotropium bromide. Am J Respir Crit Care Med. 2008;177(1):19-26.

12. Wise RA, Anzueto A, Cotton D, et al. Tiotropium Respimat inhaler and the risk of death in COPD. N Engl J Med. 2013;369(16):1491-1501.

13. Wise RA, Anzueto A, Calverley P, et al. The Tiotropium Safety and Performance in Respimat Trial (TIOSPIR), a large scale, randomized, controlled, parallel-group trial-design and rationale. Respir Res. 2013;14:40.

14. Global Initiative for Chronic Obstructive Lung Disease. Global Strategy for the Diagnosis, Management, and Prevention of Chronic Obstructive Pulmonary Disease: 2016 Report. Available from: http://goldcopd. org/global-strategy-diagnosis-management-prevention-copd-2016/. Accessed April 27, 2016.

15. Hurst JR, Vestbo J, Anzueto A, et al. Susceptibility to exacerbation in chronic obstructive pulmonary disease. $N$ Engl J Med. 2010;363(12): $1128-1138$.

16. Vezzoli S, Jones P, Corradi M, et al. Patterns of symptom change measured using the EXACT diary associated with prescription of corticosteroids or antibiotics in COPD exacerbations. Eur Respir J. 2015; 46(Suppl 59):OA1969.

17. Wilson R, Anzueto A, Miravitlles M, et al. Moxifloxacin versus amoxicillin/clavulanic acid in outpatient acute exacerbations of COPD: MAESTRAL results. Eur Respir J. 2012;40(1):17-27.

18. Almagro P, Calbo E, Ochoa de Echaguen A, et al. Mortality after hospitalization for COPD. Chest. 2002;121(5):1441-1448.

19. Groenewegen KH, Schols AM, Wouters EF. Mortality and mortalityrelated factors after hospitalization for acute exacerbation of COPD. Chest. 2003;124(2):459-467.

20. Roche N, Zureik M, Soussan D, Neukirch F, Perrotin D. Predictors of outcomes in COPD exacerbation cases presenting to the emergency department. Eur Respir J. 2008;32(4):953-961.

21. Toft-Petersen A, Torp-Pedersen C, Weinreich UM, Rasmussen BS. Assisted ventilation in COPD - association between previous hospitalizations and mortality. Int J Chron Obstruct Pulmon Dis. 2016;11: 935-943.

22. Suissa S, Ernst P, Vandemheen KL, Aaron SD. Methodological issues in therapeutic trials of chronic obstructive pulmonary disease. Eur Respir J. 2008;31:927-933.

23. Kew KM, Dias S, Cates CJ. Long-acting inhaled therapy (beta-agonists, anticholinergics and steroids) for COPD: a network meta-analysis. Cochrane Database Syst Rev. 2014;3:CD010844.

24. Yang IA, Clarke MS, Sim EH, Fong KM. Inhaled corticosteroids for stable chronic obstructive pulmonary disease. Cochrane Database Syst Rev. 2012;7:CD002991. 
25. Llor C, Moragas A, Miravitlles M; ESAB study. Usefulness of a patient symptom diary card in the monitoring of exacerbations of chronic bronchitis and chronic obstructive pulmonary disease. Int J Clin Pract. 2012;66(7):711-717.

26. Donaldson GC, Law M, Kowlessar B, et al. Impact of prolonged exacerbation recovery in chronic obstructive pulmonary disease. Am J Respir Crit Care Med. 2015;192(8):943-950.

27. Bateman ED, Rabe KF, Calverley PM, et al. Roflumilast with longacting beta2-agonists for COPD: influence of exacerbation history. Eur Respir J. 2011;38(3):553-560.
28. Vogelmeier C, Hederer B, Glaab T, et al. Tiotropium versus salmeterol for the prevention of exacerbations of COPD. $N$ Engl J Med. 2011; 364(12):1093-1103.

29. Martinez FJ, Calverley PM, Goehring UM, Brose M, Fabbri LM, Rabe KF. Effect of roflumilast on exacerbations in patients with severe chronic obstructive pulmonary disease uncontrolled by combination therapy (REACT): a multicentre randomised controlled trial. Lancet. 2015;385(9971):857-866 


\section{Supplementary material}

Table SI Time to subsequent event adjusted for inhaled corticosteroid use and exacerbation history

\begin{tabular}{|c|c|c|c|c|}
\hline \multirow[t]{3}{*}{ Subsequent event } & \multicolumn{4}{|c|}{ Index on-treatment exacerbation } \\
\hline & \multicolumn{3}{|l|}{ Moderate } & \multirow{2}{*}{$\begin{array}{l}\text { Severe } \\
\text { (requiring } \\
\text { hospitalization) }\end{array}$} \\
\hline & $\begin{array}{l}\text { Treated with } \\
\text { antibiotics only }\end{array}$ & $\begin{array}{l}\text { Treated with } \\
\text { systemic } \\
\text { corticosteroids } \\
\text { only }\end{array}$ & $\begin{array}{l}\text { Treated with } \\
\text { antibiotics } \\
\text { and systemic } \\
\text { corticosteroids }\end{array}$ & \\
\hline $\begin{array}{l}\text { No of patients in the exacerbation } \\
\text { analysis }\end{array}$ & $\mathrm{N}=3,028$ & $\mathrm{~N}=791$ & $\mathrm{~N}=2,577$ & $\mathrm{~N}=1,359$ \\
\hline Moderate to severe exacerbation, n (\%) & $\mathrm{I}, 63 \mathrm{I}(53.9)$ & $450(56.9)$ & $1,610(62.5)$ & $700(5 \mid .5)$ \\
\hline $\begin{array}{l}\text { HR versus antibiotics only }(95 \% \mathrm{Cl}) \text {, } \\
P \text {-value }\end{array}$ & - & $\begin{array}{l}1.21(1.09-1.34) \\
0.0004\end{array}$ & $\begin{array}{l}1.33(1.24-1.43) \\
<0.0001\end{array}$ & $\begin{array}{l}1.06(0.97-1.16) \\
0.18\end{array}$ \\
\hline $\begin{array}{l}\mathrm{HR} \text { versus hospitalized }(95 \% \mathrm{Cl}) \\
P \text {-value }\end{array}$ & $\begin{array}{l}0.94(0.86-1.03) \\
0.18\end{array}$ & $\begin{array}{l}1.14(1.01-1.28) \\
0.03\end{array}$ & $\begin{array}{l}1.25(1.15-1.37) \\
<0.000 \mathrm{I}\end{array}$ & - \\
\hline Severe exacerbation, $\mathrm{n}(\%)$ & $355(11.7)$ & $135(17.1)$ & $478(18.5)$ & $483(35.5)$ \\
\hline $\begin{array}{l}\text { HR versus antibiotics only }(95 \% \mathrm{Cl}) \text {, } \\
\text { P-value }\end{array}$ & - & $\begin{array}{l}1.59(1.30-1.94) \\
<0.0001\end{array}$ & $\begin{array}{l}\mathrm{I} .63(\mathrm{I} .42-1.87) \\
<0.000 \mathrm{I}\end{array}$ & $\begin{array}{l}4.31(3.76-4.95) \\
<0.0001\end{array}$ \\
\hline $\begin{array}{l}\text { HR versus hospitalized }(95 \% \mathrm{Cl}) \text {, } \\
\text { P-value }\end{array}$ & $\begin{array}{l}0.23(0.20-0.27) \\
<0.0001\end{array}$ & $\begin{array}{l}0.37(0.3 \mathrm{I}-0.45) \\
<0.000 \mathrm{I}\end{array}$ & $\begin{array}{l}0.38(0.33-0.43) \\
<0.000 \text { I }\end{array}$ & - \\
\hline $\begin{array}{l}\text { No of patients in the hospitalization, } \\
\text { death, and discontinuation analysis }\end{array}$ & $\mathrm{N}=3,070$ & $N=820$ & $N=2,660$ & $\mathrm{~N}=1,486$ \\
\hline Hospitalization (all-cause), n (\%) & $772(25.1)$ & $242(29.5)$ & $838(3 \mid .5)$ & $758(51.0)$ \\
\hline $\begin{array}{l}\text { HR versus antibiotics only }(95 \% \mathrm{Cl}) \text {, } \\
P \text {-value }\end{array}$ & - & $\begin{array}{l}\mathrm{I} .29(\mathrm{I} . \mathrm{II}-\mathrm{I} .49) \\
0.0007\end{array}$ & $\begin{array}{l}\mathrm{I} .32(\mathrm{I} .20-\mathrm{I} .45) \\
<0.000 \mathrm{I}\end{array}$ & $\begin{array}{l}3.35(3.03-3.70) \\
<0.0001\end{array}$ \\
\hline $\begin{array}{l}\text { HR versus hospitalized }(95 \% \mathrm{Cl}) \text {, } \\
P \text {-value }\end{array}$ & $\begin{array}{l}0.30(0.27-0.33) \\
<0.0001\end{array}$ & $\begin{array}{l}0.38(0.33-0.44) \\
<0.0001\end{array}$ & $\begin{array}{l}0.39(0.36-0.44) \\
<0.000 \text { I }\end{array}$ & - \\
\hline Death (all-cause), n (\%) & $164(5.3)$ & $64(7.8)$ & $209(7.9)$ & $240(16.2)$ \\
\hline $\begin{array}{l}\text { HR versus antibiotics only }(95 \% \mathrm{Cl}) \text {, } \\
P \text {-value }\end{array}$ & - & $\begin{array}{l}1.50(1.12-2.00) \\
0.0059\end{array}$ & $\begin{array}{l}1.47(1.20-1.80) \\
0.0002\end{array}$ & $\begin{array}{l}3.53(2.90-4.31) \\
<0.0001\end{array}$ \\
\hline $\begin{array}{l}\text { HR versus hospitalized }(95 \% \mathrm{Cl}) \text {, } \\
P \text {-value }\end{array}$ & $\begin{array}{l}0.28(0.23-0.35) \\
<0.0001\end{array}$ & $\begin{array}{l}0.43(0.32-0.56) \\
<0.0001\end{array}$ & $\begin{array}{l}0.42(0.35-0.50) \\
<0.0001\end{array}$ & - \\
\hline Death due to COPD, n (\%) & $45(1.5)$ & $26(3.2)$ & $85(3.2)$ & $106(7.1)$ \\
\hline $\begin{array}{l}\text { HR versus antibiotics only }(95 \% \mathrm{Cl}) \text {, } \\
\text { P-value }\end{array}$ & - & $\begin{array}{l}2.23(1.38-3.62) \\
0.0011\end{array}$ & $\begin{array}{l}2.15(1.50-3.09) \\
<0.0001\end{array}$ & $\begin{array}{l}5.54(3.91-7.86) \\
<0.0001\end{array}$ \\
\hline $\begin{array}{l}\text { HR versus hospitalized }(95 \% \mathrm{Cl}) \text {, } \\
P \text {-value }\end{array}$ & $\begin{array}{l}0.18(0.13-0.26) \\
<0.0001\end{array}$ & $\begin{array}{l}0.40(0.26-0.62) \\
<0.0001\end{array}$ & $\begin{array}{l}0.39(0.29-0.52) \\
<0.0001\end{array}$ & - \\
\hline Discontinuation, $\mathrm{n}(\%)$ & $435(14.2)$ & $162(19.8)$ & $509(19.1)$ & $434(29.2)$ \\
\hline $\begin{array}{l}\text { HR versus antibiotics only }(95 \% \mathrm{Cl}) \text {, } \\
P \text {-value }\end{array}$ & - & $\begin{array}{l}\text { I.46 (I.22-1.75) } \\
<0.000 \mathrm{I}\end{array}$ & $\begin{array}{l}1.38(1.2 \mathrm{I}-1.56) \\
<0.000 \mathrm{I}\end{array}$ & $\begin{array}{l}2.52(2.2 \mathrm{I}-2.88) \\
<0.000 \mathrm{I}\end{array}$ \\
\hline $\begin{array}{l}\text { HR versus hospitalized }(95 \% \mathrm{Cl}) \text {, } \\
P \text {-value }\end{array}$ & $\begin{array}{l}0.40(0.35-0.45) \\
<0.0001\end{array}$ & $\begin{array}{l}0.58(0.48-0.69) \\
<0.0001\end{array}$ & $\begin{array}{l}0.55(0.48-0.62) \\
<0.000 \text { I }\end{array}$ & - \\
\hline
\end{tabular}

Notes: Time at risk of subsequent exacerbation started the day after the end of the first exacerbation and ended at treatment stop. Time at risk of subsequent hospitalization, discontinuation, or death started the day after the start of the first exacerbation and ended at treatment stop +30 days (or death) (for hospitalization), treatment stop (for discontinuation), or at last known date alive or death (for death).

International Journal of COPD

\section{Publish your work in this journal}

The International Journal of COPD is an international, peer-reviewed journal of therapeutics and pharmacology focusing on concise rapid reporting of clinical studies and reviews in COPD. Special focus is given to the pathophysiological processes underlying the disease, intervention programs, patient focused education, and self management protocols.

\section{Dovepress}

This journal is indexed on PubMed Central, MedLine and CAS. The manuscript management system is completely online and includes a very quick and fair peer-review system, which is all easy to use. Visit $\mathrm{http} / / / \mathrm{www}$.dovepress.com/testimonials.php to read real quotes from published authors. 